This is the pre-peer reviewed version of the following article:

From the $\mathrm{Ca}^{2+}$-activated $\mathrm{F}_{1} \mathrm{Fo}_{\mathrm{O}}$-ATPase to the mitochondrial permeability transition pore: an overview.

Nesci S, Trombetti F, Ventrella V, Pagliarani A.

Biochimie. 2018 Sep;152:85-93.

The final published version is available online at:

https://doi.org/10.1016/j.biochi.2018.06.022 


\title{
From the $\mathrm{Ca}^{2+}$-activated $\mathrm{F}_{1} \mathrm{~F}_{\mathrm{O}}$-ATPase to the mitochondrial permeability transition pore: an overview
}

\author{
Salvatore Nesci, Fabiana Trombetti, Vittoria Ventrella, Alessandra Pagliarani
}

Department of Veterinary Medical Sciences, University of Bologna, via Tolara di Sopra 50, 40064 Ozzano Emilia (BO) - Italy

Corresponding author: Alessandra Pagliarani, alessandra.pagliarani@unibo.it

Declaration of interest: none 


\begin{abstract}
Based on recent advances on the $\mathrm{Ca}^{2+}$-activated $\mathrm{F}_{1} \mathrm{~F}_{\mathrm{O}}$-ATPase features, a novel multistep mechanism involving the mitochondrial $\mathrm{F}_{1} \mathrm{~F}_{\mathrm{O}}$ complex in the formation and opening of the still enigmatic mitochondrial permeability transition pore (MPTP), is proposed. MPTP opening makes the inner mitochondrial membrane (IMM) permeable to ions and solutes and, through cascade events, addresses cell fate to death. Since MPTP forms when matrix $\mathrm{Ca}^{2+}$ concentration rises and ATP is hydrolyzed by the $\mathrm{F}_{1} \mathrm{~F}_{\mathrm{O}}$-ATPase, conformational changes, triggered by $\mathrm{Ca}^{2+}$ insertion in $\mathrm{F}_{1}$, may be transmitted to $F_{O}$ and locally modify the IMM curvature. These events would cause $F_{1} F_{O^{-}}$ ATPase dimer dissociation and MPTP opening.
\end{abstract}

Keywords: $\mathrm{F}_{1} \mathrm{~F}_{\mathrm{O}}$-ATPase; calcium ion; mitochondrial permeability transition pore; conformational mechanism 


\section{Introduction}

Oxidative phosphorylation, which features mitochondria in eukaryotes, is based on the cooperation and interplay between multiple enzyme complexes. Briefly, these complexes are dehydrogenases which transfer electrons according to the electrochemical gradient from reduced respiratory substrates, namely $\mathrm{NADH}$ and $\mathrm{FADH}_{2}$, to the final acceptor molecular oxygen, and, by pumping protons in the intermembrane space, generate a $\mathrm{H}^{+}$current through the inner mitochondrial membrane (IMM). Finally, the transmembrane electrochemical gradient of $\mathrm{H}^{+}\left(\Delta \mu_{\mathrm{H}^{+}}\right)$created by respiratory chain substrate oxidation drives ATP synthesis by the ATP synthase [1]. The formation of a large channel in the IMM, namely the so-called mitochondrial permeability transition pore (MPTP), dissipates the $\Delta \mu_{\mathrm{H}^{+}}$and, differently from the accepted bases of chemiosmotic hypothesis [2], eludes ATP production and causes loss of substrates and nucleotides from the mitochondrial matrix [3]. MPTP opening, by dramatically changing the IMM electrophysiological features, leads to mitochondrial dysfunction. The MPTP regulation and role in different forms of cell death, including autophagy, and in various pathologies have been the subject of intense and fruitful research, sustained by the hope to exploit this mitochondrial event to fight cancer, ischemic damage and neurodegeneration [4]. On the other hand, recent studies suggest that the MPTP may also play a relevant role in mitochondrial function, cell differentiation and development [5]. The MPTP structure has long remained a mystery, even if its identity was intensively searched for among known membrane components, above all membrane-bound proteins. At first, the voltage-dependent anion channel (VDAC) and the peripheral benzodiazepine receptor on the outer mitochondrial membrane (OMM) together with the IMM adenine nucleotide translocase (ANT) seemed the most likely candidates to take part in the enigmatic mechanism of MPTP formation [6]. In this putative mechanism, ANT was thought to constitute the MPTP fulcrum since the ANT inhibitors atractyloside (ATR) and bongkrekic acid (BGK) modulated the MPTP. In detail, BGK inhibited the MPTP by locking ANT in the M conformation (closed MPTP), while ATR maintained it in the C conformation (open MPTP) [7]. However, the ANT channel showed a similar conductance to that of the MPTP [8]. Subsequent findings pointed out that MPTP formation involved a supra-molecular complex, namely the assembly of different proteins [9]. Accordingly, differently localized proteins, namely hexokinase bound to the cytosolic surface of OMM, creatine kinase and nucleoside diphosphate kinase in the intermembrane space, and cyclophilin $\mathrm{D}(\mathrm{CypD})$ in the matrix apparently contributed to form the MPTP. An alternative model, in which the $P_{i}$ carrier by interacting with ANT and CypD induced MPTP opening, was depicted [10]. However all the models proposed over 40 years of studies did not fully match the electrophysiological MPTP features [4] or were undermined by genetic deletion tests, which, one by one, excluded that any of these proteins are essential for MPTP formation [11-14]. ANT, the $\mathrm{P}_{\mathrm{i}}$ carrier and the $\mathrm{F}_{1} \mathrm{~F}_{\mathrm{O}}$-ATPase may mutually interact through cardiolipin which would somehow connect these proteins to form the ATP synthasome. Consistently, conformational changes triggered by $\mathrm{Ca}^{2+}$ within the ATP synthasome may perturb the interface between these structures and produce the pore [15]. The ATP synthasome dynamics is ruled by the metabolic demand and is CypD-dependent [16]. Moreover, changes in the contact sites between the inner and outer mitochondrial membranes could intervene in MPTP opening [15]. At present, it seems likely that the MPTP may coincide with a conserved mitochondrial protein of key role in mitochondria. Recently, the $\mathrm{F}_{1} \mathrm{~F}_{\mathrm{O}}$-ATPase -a splendid molecular machine- [17] has been proposed to form the pore structure $[18,19]$.

\section{The $\mathrm{F}_{1} \mathrm{~F}_{\mathrm{O}}$-ATPase: from an old to a new story as pore former}


From its discovery around the middle of the $20^{\text {th }}$ century, the $\mathrm{F}_{1} \mathrm{~F}_{\mathrm{O}}$-ATPase has undergone a sort of on-going evolution, stimulated by the increasing development of techniques and of knowledge, which lead to a continuous re-evaluation of the roles of this intriguing enzyme complex [17,20]. At present, we can say that new and up to now unsuspected roles for this ubiquitous enzyme are emerging in mitochondria. As widely known, in eukaryotic mitochondria the $\mathrm{F}_{1} \mathrm{~F}_{\mathrm{O}}$-ATPase constitutes the amazing molecular machine that exploits the electrochemical energy produced by the respiratory chain in the form of Mitchell's proton motive force $(\Delta p)$ to produce ATP via a chemomechanical coupling mechanism [21]. Even if ATP synthesis represents the classical enzyme task, the catalytic mechanism is long known to work also in reverse to energize the IMM by ATP hydrolysis [20,22]. In practice, the direction of catalysis depends on $\Delta p$, being ATP synthesized to dissipate $\Delta p$ and conversely ATP hydrolyzed to re-build $\Delta p$. The $\mathrm{F}_{1} \mathrm{~F}_{\mathrm{O}}$-ATPase structure is quite complex and can be roughly defined as an oligomer structurally composed by a hydrophilic $\mathrm{F}_{1}$ catalytic domain and by a membrane-embedded $\mathrm{F}_{\mathrm{O}}$ domain. These two domains are joined by a central and a peripheral stalk (Fig. 1). In turn the $\mathrm{F}_{1}$ sector, which protrudes in the mitochondrial matrix, shows a $\alpha_{3} \beta_{3} \gamma \delta \varepsilon$ subunit composition and stoichiometry [23]. The three $\alpha$ subunits alternate with three $\beta$ subunits to form the $\mathrm{F}_{1}$ globular hexamer. The adenine nucleotide binding sites, namely three non-catalytic sites on $\alpha$ subunits and three catalytic sites on the $\beta$ subunits, open at the interfaces between the $\alpha$ and $\beta$ subunits of this spherical complex [24]. The membrane-embedded $\mathrm{F}_{\mathrm{O}}$ sector is also formed by multiple proteins, namely the $a$ subunit, the short amphipathic $b$ subunit with the two transmembrane $\alpha$-helices, $e, f, g$, A6L, DAPIT (diabetes-associated protein in insulinsensitive tissue) subunits, a $6.8 \mathrm{kDa}$ proteolipid and the $c_{\mathrm{n}}$-ring, in which the subunit number is species-dependent $[25,26]$. The $\gamma$ subunit extends from the center of the $(\alpha \beta)_{3}$ structure of $F_{1}$ to the $\mathrm{F}_{\mathrm{O}}$ domain where it joins the $\delta$ and the $\varepsilon$ subunits to form the foot of central stalk [27]. The core of $\mathrm{F}_{\mathrm{O}}$ is formed by the $c$-ring, which is directly attached to the central stalk and constitutes the enzyme rotor, which transmits the rotational energy to $\mathrm{F}_{1}$. Laterally, the $b, d, \mathrm{~F}_{6}$ and OSCP subunits form the peripheral stalk, which not only links the $(\alpha \beta)_{3}$-catalytic structure to the $a$ subunit in the $\mathrm{F}_{\mathrm{O}}$ domain, forming the integral enzyme stator, but also plays the role of resisting the torque generation of rotor [28]. Actually, the $\mathrm{F}_{1} \mathrm{~F}_{\mathrm{O}} \mathrm{ATPase} / \mathrm{synthase}$ is a rotary engine which matches rotation to catalysis. The clockwise rotation (seen from the intermembrane space) is driven by $\Delta p$ which makes $\mathrm{H}^{+}$downhill translocate across the IMM through the $a$ subunit/c-ring complex interface. This rotation transmitted from $\mathrm{F}_{\mathrm{O}}$ to $\mathrm{F}_{1}$ produces one ATP molecule per each $\beta$ subunit, namely three ATP molecules are built in a $360^{\circ}$ cycle. The opposite rotation, which pumps $\mathrm{H}^{+}$, in the intermembrane space and re-constitutes $\Delta p$, is coupled to ATP hydrolysis. The nucleotide binding in the catalytic site requires the coordination of the essential cofactor $\mathrm{Mg}^{2+}$, which contributes to ATP synthesis/hydrolysis and to the asymmetry of the three catalytic sites, which produces the differences in affinity for nucleotides [29]. Accordingly, each $\beta$ subunit is asymmetric and during the rotation, by interacting with the $\gamma$ subunit, undergoes three distinct conformational states $\beta_{\mathrm{E}}$ (always empty), $\beta_{\mathrm{DP}}$, which contains bound MgADP and $\beta_{\mathrm{TP}}$ which binds MgATP [30].

Interestingly, in mitochondria, the $\mathrm{F}_{1} \mathrm{~F}_{\mathrm{O}}$-ATPases are assembled in supra-molecular dimeric complexes by the transmembrane $\mathrm{F}_{\mathrm{O}}$ domain [31] which form extensive rows [32,33] distributed along the tightly curved ridges of the IMM cristae [34]. This localization exploits the higher $\mathrm{H}^{+}$ density on the surface in the curved membrane regions [35] created by the respiratory complexes crowding at either side of the rows [36]. Structure, localization and function are tightly connected. Accordingly, the $\mathrm{F}_{1} \mathrm{~F}_{\mathrm{O}}$-ATPase structural arrangement and localization have relevant implications for the mechanism of mitochondrial energy transduction [34] and substantiate the $\mathrm{F}_{1} \mathrm{~F}_{\mathrm{O}}$-ATPase active role in membrane bending and cristae formation [35,37], thus contributing to mitochondrial 
morphology. Indeed, the enzyme complex assembly locally produces an extreme membrane

The $\mathrm{F}_{1} \mathrm{~F}_{\mathrm{O}}$-ATPase energy-transduction mechanism of bioenergetics [22] and its modeling ability on mitochondria [38] turns into an energy-dissipating machinery when the mitochondrial $\mathrm{Ca}^{2+}$ concentration abruptly increases under pathological conditions [39]. In this case the $\mathrm{F}_{1} \mathrm{~F}_{\mathrm{O}}$-ATPase activated by $\mathrm{Ca}^{2+}$ instead of $\mathrm{Mg}^{2+}$ would form a channel which matches the conductance properties of the MPTP $[40,41]$. The pore opening leads to transient IMM depolarization and allows the diffusion of solutes, water enters and ATP is hydrolyzed by the $\mathrm{F}_{1} \mathrm{~F}_{\mathrm{O}}$-ATPase [3]. Disruption of mitochondrial homeostasis induces swelling and bursting of IMM, an event which has been linked to pathways leading to cell death $[42,43]$. The MPTP opening has been reported to be affected by a large variety of effectors and conditions, spanning from ion concentrations to physical changes. Accordingly, $\mathrm{Ca}^{2+}, \mathrm{Mg}^{2+}$, adenine nucleotides, $\mathrm{P}_{\mathrm{i}}, \mathrm{H}^{+}$and membrane potential have been claimed as $\mathrm{F}_{1} \mathrm{~F}_{\mathrm{O}}$-ATPase modulators and MPTP inducers/inhibitors [44]. On considering that the $\mathrm{F}_{1} \mathrm{~F}_{\mathrm{O}}$-ATPase is not only ruled by its own substrates/products, but also responds to post-translational modifications (PTMs) on different subunits [30], PTMs affecting the enzyme function or its supercomplex organization may greatly impact MPTP modulation [44]. Furthermore, cyclosporin A (CsA) blocks the MPTP binding to CyPD, a protein which modulates the MPTP without being an essential component of its structure [45,46]. Additionally, the putative MPTP-CypD interaction involves OSCP subunit of $F_{1}$ sector [47], which connects the catalytic $(\alpha \beta)_{3}$ spherical complex to the peripheral stalk. However, since MPTP opening was recently reported to remain CsA-sensitive also in the absence of OSCP [48] or pH-dependent by protonation of the unique histidine in OSCP subunit [49], the whole mechanism need to be clarified.

On balance, the experimental evidence accumulated up to now points out that the MPTP-forming properties in eukaryotes [50] are apparently linked to the dual $\mathrm{F}_{1} \mathrm{~F}_{\mathrm{O}}$-ATPase function. Even if some points remain controversial and require to be elucidated, the enzyme of life that synthesizes ATP, activated by $\mathrm{Mg}^{2+}$, apparently turns into the enzyme of death when hydrolyzes ATP in the presence of $\mathrm{Ca}^{2+}$.

\section{The hypotheses on the $\mathrm{F}_{1} \mathrm{~F}_{\mathrm{O}}$-ATPase involvement in the MPTP}

From the beginning of the story, namely since cell death was associated with an abruptly increased mitochondrial permeability, it seemed quite obvious that the pore formation should involve mitochondrial membrane components whose conformational changes under certain conditions eventually made the inner membrane itself permeable to water and solutes. The most likely candidates were membrane-bound proteins, since the pore always supposed to be proteinaceous $[4,44]$. However, the MPTP constitution was never elucidated and it was also proposed to include a non-proteinaceous ion-conducting module [51]. Assumed that the $\mathrm{F}_{1} \mathrm{~F}_{\mathrm{O}}$-ATPase contributes to MPTP formation, as recent advances strongly hint, up to now two main mechanisms have been hypothesized: the channel forms within the $c$-ring of the $\mathrm{F}_{\mathrm{O}}$ sector [52] or, alternatively, at the interface between the contact region of the dimer [19].

The "c-ring hypothesis" is sustained by intriguing hints on the channel conductance, obtained on mammalian pure $c$ subunits reconstituted in lipid bilayers capable of generating spontaneous electrical oscillations activated by cGMP and inhibited by $\mathrm{Ca}^{2+}[53]$. However, the current 
generated through the $c$ subunit pore was found to be cation-selective [54], while the MPTP is $1,500 \mathrm{Da}$ [55]. Otherwise, the dephosphorylation of a peptide related to $c$ subunits promoted by $\mathrm{Ca}^{2+}$ and prevented by CsA emerged as MPTP inducer [56]. The formation of a voltage-sensitive channel in reconstituted $c$ subunits or purified $\mathrm{F}_{1} \mathrm{~F}_{\mathrm{O}}$-ATPase in liposomes was hypothesized. The pore would be formed by CyPD and $\mathrm{Ca}^{2+}$-dependent $c$-ring expansion and $\mathrm{F}_{1}$ detachment [52]. This multi-conductance channel lacked cation selectivity, but was resistant to $\mathrm{CsA}$, insensitive to $\mathrm{Ca}^{2+}$ and inhibited by the $\beta$ subunit of $\mathrm{F}_{1} \mathrm{~F}_{\mathrm{O}}$-ATPase [52]. Experiments of overexpression or depletion of endogenous $c$ subunits by specific siRNA downregulation and consequent MPTP inactivation strengthened the " $c$-ring channel" hypothesis [18]. A proper $c$-ring conformation is required for MPTP opening [57] and the highly conserved $c$ subunit Gly zipper domain apparently plays a key role in the $c$-ring assembly linked to MPTP sensitivity [52,57]. Recent insights are provided by the $\mathrm{Ca}^{2+}$-induced de novo water-permeable MPTP complex, which is inhibited by CsA, and apparently made up by $c$ subunits associated with polyphosphate (polyPi) and polyhydroxybutyrate (PHB) [58]. The interaction of the $c$ subunits with polyPi and PHB, by generating a charged polymer, provides an environment compatible with the hydrophobicity of these proteolipids. Indeed, the $c$ ring ion conduction gaps were offset by the electrophysiological properties of the non-proteinaceous $\mathrm{Ca}^{2+}$-selective polyPi/PHB channel [51]. Otherwise, due to its structure, the $c$-ring cannot form a water-filled channel as suggested by the atomistic simulations of two $c$-rings of different lumen width [59]. The $c$-ring lumen contains lipids in bacteria [60], while in mitochondria it would be occluded by lipid molecules and forms a non-conducting channel [59]. Moreover, even in a potentially conducting state (i.e. hydrated state of the $c$-ring interior), molecular dynamics simulations demonstrated that the biophysical properties of such channel were not consistent with the high ionic conductance attributed to the MPTP [59]. However, atomic simulations on the $c$-ring do not take the polyPi/PHB model into account. Accordingly, due to the PHB amphipathic properties, lipids may localize in the $c$-ring hydrophobic core and even allow ion flux [58]. Even if the structural bases of the "c-ring channel" opening [52] necessarily require CyPD binding and inhibition by CsA only after $\mathrm{Ca}^{2+}$ addition, CyPD-null mice showed electrophysiological MPTP features indistinguishable from those of wild-type individuals in presence of high $\mathrm{Ca}^{2+}$ loads $[61,62]$. The possibility that the channel may be opened by the displacement of the two main $\mathrm{F}_{1} \mathrm{~F}_{\mathrm{O}^{-}}$ ATPase domains has also been considered. However, strip down $F_{1}$ from $F_{O}$ sector generally occurs under drastic conditions, for instance in the presence of high urea concentrations, and leads to irreversible $\mathrm{F}_{1} \mathrm{~F}_{\mathrm{O}}$-ATPase denaturation, whereas the MPTP reversibly shifts between open/closed states. Moreover, the displacement of the two $\mathrm{F}_{1} \mathrm{~F}_{\mathrm{O}}$-ATPase sectors is not a likely mechanism to create a channel within $\mathrm{F}_{\mathrm{O}}$, because the $\gamma, \delta$ and $\varepsilon$ subunits of $\mathrm{F}_{1}$ cannot return to their native position within the hydrophobic sector. Additionally, it seems difficult to think that free $\beta$ subunits can inhibit the MPTP formation because the catalytic subunits are linked into $(\alpha \beta)_{3}$ globular hexamer resistant to denaturation, yet the hexamer does not interact with the embedded membrane sector in wild-type $\mathrm{F}_{1} \mathrm{~F}_{\mathrm{O}}$-ATPase [63]. Finally, human cells in which the $c$ subunit genes are disrupted preserve the typical MPTP properties [64]. These vestigial $\mathrm{F}_{1} \mathrm{~F}_{\mathrm{O}}$-ATPases in cells unable to synthesize the $c$ subunits are also structurally devoid of $a$ and A6L subunits and cannot translocate $\mathrm{H}^{+}$, even if the CsA-sensitive MPTP formation is maintained [64]. On these bases it seems reasonable to conclude that in the absence of $c$ subunits the MPTP could be formed and be sensitive to $\mathrm{CypD}$, but it remains unclear if its conductance properties occurs through an unregulated MPTP pathway or not [65]. 
If the "c-ring hypothesis", even if intriguing, show some inconsistencies, other recent findings formation was observed after reconstitution into lipid bilayers of gel-purified $\mathrm{F}_{1} \mathrm{~F}_{\mathrm{O}}$-ATPase dimers associated with the detection of an indistinguishable channel current ascribable the MPTP electrophysiological equivalent mitochondrial mega-channel [19]. Cross-linking experiments from Bernardi's group indicate that the OSCP subunit of peripheral stalk interacts with CyPD [47] and benzodiazepine 423 (Bz-423), a MPTP inducer which overlaps the CyPD binding site [19]. Bz-423 inhibits the $\mathrm{F}_{1} \mathrm{~F}_{\mathrm{O}}$-ATPase activity similarly to the $\mathrm{P}_{\mathrm{i}}$-dependent $\mathrm{CyPD}$ which, by binding to the OSCP subunit, decreases the $\mathrm{Mg}^{2+}$-dependent ATP hydrolysis in the absence of CsA [47]. Thus, CyPD modulates MPTP opening and CyPD binding to OSCP may propagate the conformational changes of the catalytic sites through the stator to enzyme membrane portions [66]. The high matrix $\mathrm{Ca}^{2+}$ concentration features MPTP activation. Therefore the " $\mathrm{F}_{1} \mathrm{~F}_{\mathrm{O}}$-ATPase peripheral stalk/dimer hypothesis" is fully consistent with the occupation of the catalytic site by $\mathrm{Ca}^{2+}$ in replacement of natural cofactor $\mathrm{Mg}^{2+}[44,66]$. In the catalytic site the ${ }_{\beta} \mathrm{Thr}^{163}$ of the P-loop is directly linked to $\mathrm{Mg}^{2+}$, while the ${ }_{\beta} \mathrm{Arg}^{189},{ }_{\beta} \mathrm{Glu}^{192},{ }_{\beta} \mathrm{Asp}^{256}$ residues are coordinated with $\mathrm{Mg}^{2+}$ by three water molecules respectively [67] (Fig. 2b). The metal binding pocket can be occupied by other divalent cations such as $\mathrm{Ca}^{2+}$ [68]. Interestingly, experiments on prokaryotes showed that the single mutation of ${ }_{\beta} \mathrm{Thr}^{159} \mathrm{Ser}$ at the catalytic site equivalent to ${ }_{\beta} \mathrm{Thr}{ }^{163} \mathrm{Ser}$ in eukaryotes is the only aminoacid substitution which allows the normal $\mathrm{F}_{1} \mathrm{~F}_{\mathrm{O}}$-ATPase function if sustained by MgATP, but not by CaATP [69]. A recent paper [70] investigated the effects of the ${ }_{\beta} \mathrm{Thr}^{163}$ Ser mutation in human $\mathrm{F}_{1} \mathrm{~F}_{\mathrm{O}^{-}}$ ATPase. In comparison with wild type mitochondria, ATP hydrolysis driven by $\mathrm{Mg}^{2+}$ was stimulated, while the $\mathrm{Ca}^{2+}$-dependent $\mathrm{F}_{1} \mathrm{~F}_{\mathrm{O}}$-ATPase activity was nearly completely inhibited. Moreover, the mutation in $\beta$ subunit apparently decreased the MPTP sensitivity to $\mathrm{Ca}^{2+}$, since higher $\mathrm{Ca}^{2+}$ levels were required to induce MPTP opening [70]. The ${ }_{\beta} \mathrm{Thr}^{163}$ is probably the only aminoacid which directly binds to the metal cation in the catalytic site. Consistently, while in presence of $\mathrm{Mg}^{2+}$ the mutation in the catalytic subunit apparently favors ADP release during hydrolysis, the larger $\mathrm{Ca}^{2+}$ would cause a spatial rearrangement that stiffens the $\mathrm{F}_{1}$ sector and limits OSCP motility. Molecular dynamics simulations suggest that the mechanical energy of $\mathrm{Ca}^{2+}$ bound to $\beta$-subunits sites may be transmitted through a long connecting loop to the "crown region" of the OSCP subunit (Fig. 2a). According to this mechanism, the motion starting from the catalytic sites would be transferred through the lateral stalk to the membrane subunits where the MPTP opens [70]. Looking at the residues putatively involved in this mechanism, some concern might arise about the $\mathrm{Ca}^{2+}$ specific conformational changes transmission from the catalytic binding sites to OSCP, since only the N-terminus of the three $\alpha$ subunits interacts with OSCP at the N-terminal $\alpha$ helical domain. Other interactions between the $(\alpha \beta)_{3}$ spherical domain and the peripheral stalk are established, connecting the $\alpha$ subunit $\mathrm{N}$-terminal region to $b$ and $\mathrm{F}_{6}$ subunits respectively and the $\alpha$ subunit C-terminus to $d$ subunit [38,71]. However, He et al, [48] recently provided experimental evidence that peripheral stalk subunits (i.e. OSCP and $b$ subunit) are not involved in the MPTP formation. Consistently, the $\mathrm{F}_{1}$ modification induced by $\mathrm{Ca}^{2+}$ cannot be transmitted to the membrane subunits when the stator is defective. In cells with $\mathrm{F}_{1} \mathrm{~F}_{\mathrm{O}}$-ATPase devoid of OSCP or if the peripheral stalk lacks the two transmembrane $\alpha$-helices of $b$ subunit, mitochondria retained a reduction of MPTP-dependent swelling rate responsive to CsA inhibition, thus suggesting that the binding site for CyPD is not provided by OSCP and in this vestigial $\mathrm{F}_{1} \mathrm{~F}_{\mathrm{O}}$-ATPase the channel size is affected [48]. Nevertheless, the inhibition of the MPTP opening by acidic pHs is sensitive to the protonation of the unique histidine in OSCP subunit (ospcHis ${ }^{112}$ in humans) [49], thus leading Antoniel and colleagues suspect that more than one subunit of the peripheral stalk can transmit the full-conductance signal for MPTP opening. In addition, the overexpression of $e$ subunit, which is 
known to promote the $\mathrm{F}_{1} \mathrm{~F}_{\mathrm{O}}$-ATPase dimerization [72,73], limits the MPTP induction by $\mathrm{Ca}^{2+}$.

\section{A new conformational transmission model for MPTP opening}

On considering the hypotheses so far proposed, some questions are still open. The MPTP, the $\mathrm{F}_{1} \mathrm{~F}_{\mathrm{O}^{-}}$ ATPase and $\mathrm{Ca}^{2+}$ depict an enigmatic triangle [74], in which $\mathrm{Ca}^{2+}$ apparently plays the leading role. From the available literature data and of some recent findings in our lab, we become increasingly convinced that $\mathrm{Ca}^{2+}$ by interacting with the $\mathrm{F}_{1} \mathrm{~F}_{\mathrm{O}}$-ATPase triggers subsequent conformational events which ultimately lead to form a pore in the inner mitochondrial membrane. In our opinion, there are many clues that lead to build an intriguing and quite realistic model. Accordingly, when the mitochondrial $\mathrm{Ca}^{2+}$ concentration increases, it replaces the natural cofactor $\mathrm{Mg}^{2+}$ in the catalytic site of the $\mathrm{F}_{1} \mathrm{~F}_{\mathrm{O}}$-ATPase [70]. As recently pointed out [75], the catalytic mechanism of ATP hydrolysis and $\mathrm{H}^{+}$translocation by the $\mathrm{Ca}^{2+}$ and $\mathrm{Mg}^{2+}$-dependent $\mathrm{F}_{1} \mathrm{~F}_{\mathrm{O}}$ complexes are apparently similar, in contrast with previous reports [76-78]. Interestingly, small molecules or cofactors (e.g. nitrite or $\mathrm{NAD}^{+}$) were found to act differently on the enzyme when it is activated by $\mathrm{Ca}^{2+}$ or by $\mathrm{Mg}^{2+}$, namely they inhibit the $\mathrm{Ca}^{2+}$-dependent $\mathrm{F}_{1} \mathrm{~F}_{\mathrm{O}}$-ATPase without affecting the $\mathrm{Mg}^{2+}$-dependent $\mathrm{F}_{1} \mathrm{~F}_{\mathrm{O}}$-ATPase. Therefore, the catalysis modulation may represent a molecular mechanism which is somehow involved in MPTP regulation [79,80]. As far as we are aware, the $\mathrm{Ca}^{2+}$-activated $\mathrm{F}_{1} \mathrm{~F}_{\mathrm{O}}$-ATPase cannot synthesize ATP, but it is capable of ATP hydrolysis, probably by adapting the catalytic mechanism, which is compatible with the greater steric hindrance of $\mathrm{Ca}^{2+}$ with respect to $\mathrm{Mg}^{2+}$ when inserted in the $\beta$ subunits [75]. So, in the presence of the larger $\mathrm{Ca}^{2+}$ radius, the coordination geometry of the cofactor-binding site of the enzyme would change from six-fold octahedral up to allow eight ligands, resulting into a less rigid geometry with irregular distances and angles [81]. The $\mathrm{Mg}^{2+}$ and $\mathrm{Ca}^{2+}$ stimulated enzyme activities, thus suggesting that the two cations similarly interact with the protein and the nucleotides $[75,81]$. Nevertheless, $\mathrm{Ca}^{2+}$ could bind to the same aminoacid residues as $\mathrm{Mg}^{2+}$ with even greater affinity (Fig. 2b,c). Moreover, ATP hydrolysis, which causes the mitochondrial ATP pool depletion associated with the MPTP [3], drives the torsional mechanism of the central stalk in the $\mathrm{Ca}^{2+}$-activated $\mathrm{F}_{1} \mathrm{~F}_{\mathrm{O}}$-ATPase [82]. This torsion is coupled to $\mathrm{H}^{+}$pumping [75] through the IMM, even if $\mathrm{H}^{+}$translocation is unable to re-energize the IMM [44,75]. As a result, when the $\mathrm{F}_{1} \mathrm{~F}_{\mathrm{O}}$-complex works in the reverse mode (ATPase) driven by $\mathrm{Ca}^{2+}$ there is ATP dissipation without membrane polarization. So, it seems reasonable to think that the $\mathrm{Ca}^{2+}$-activated $\mathrm{F}_{1} \mathrm{~F}_{0}$-ATPase can start a multistep process resulting into MPTP formation and opening [83]. According to this model, the spatial rearrangement within $\mathrm{F}_{1}$ would arise from $\mathrm{Ca}^{2+}$ binding to the catalytic sites, and, in the form of conformational change signal, would be transmitted to reach the hydrophobic $F_{O}$ sector, where it would promote the dissociation of $F_{1} F_{O}$-ATPase dimers into monomers and determine the loss of the local curvature of cristae, thus making the MPTP open (Fig. 3). These events, namely the $\mathrm{F}_{1} \mathrm{~F}_{\mathrm{O}}$-ATPase activation by $\mathrm{Ca}^{2+}$ and the deformation of cristae, are both associated with mitochondrial dysfunction and cell death due to MPTP opening. The $\mathrm{F}_{1} \mathrm{~F}_{\mathrm{O}^{-}}$ ATPase dimerization in mammalian mitochondria could arise from the $a$ and $e$ subunits, while in yeast mitochondria also $i / j$ and $k$ subunits would participate in maintaining the dimer joined. These supernumerary membrane subunits in yeasts could be functional orthologs of the 6.8 proteolipid and DAPIT subunits in mammalian mitochondrial $\mathrm{F}_{1} \mathrm{~F}_{\mathrm{O}}$-ATPase, respectively. Interestingly, two 
adjacent $a$ subunits in mammalian form a "dimerization motif" in which the $a$ subunit of each and the N-terminal portion of $b$ subunits forming an unusual transmembrane domain [31] which, when the $\mathrm{F}_{1} \mathrm{~F}_{\mathrm{O}}$-ATPase dimerizes, induces the positive curvature of the membrane which produces the morphology of the cristae. Indeed, $\mathrm{F}_{1} \mathrm{~F}_{\mathrm{O}}$-ATPase monomers are per se sufficient to produce curvature in lipid bilayers (a $43^{\circ}$ inclination is imposed by the membrane stator domain) and the detachment of dimers prevents the formation of the edge of the cristae, resulting in a zig-zag topology of the membrane [84]. Conversely, the positioning of dimers along rows in a ridge is a self-association of side-by-side union of multiple dimeric $\mathrm{F}_{1} \mathrm{~F}_{\mathrm{O}}$-ATPase super-complexes which does not require additional protein-protein interactions [35].

The stiffness of the peripheral stalk holds the $(\alpha \beta)_{3}$ globular hexamer in a stationary position with respect to the IMM, even if the stator has the adequate flexibility to allow the rotary catalytic cycle [85]. The dimer interface is formed at the basis of the peripheral stalk. Thus, any unusual flexibility induced in this structure can compromise the stability of the dimeric $\mathrm{F}_{1} \mathrm{~F}_{\mathrm{O}}$-ATPase supra-molecular assembly. However, MPTP persists in the absence of the peripheral stalk subunit [48]. Interestingly, vestigial $\mathrm{F}_{1} \mathrm{~F}_{\mathrm{O}}$-ATPase complexes, which lack the $c$-ring, the $a$ and the A6L subunit or either the $b$ subunit or the OSCP subunit, retain the MPTP features. All these vestigial enzymes were found abundantly associated with two forms of the intrinsic inhibitor protein $\left(\mathrm{IF}_{1}\right)$ [48,64]: a mature inactive $\mathrm{IF}_{1}$ form ( $\mathrm{IF}_{1}-\mathrm{M} 1$ but not the $\mathrm{IF}_{1}-\mathrm{M} 2$ isoform) and the import precursor $\mathrm{IF}_{1}, \mathrm{IF}_{1}-\mathrm{P}$ (a mature $\mathrm{IF}_{1}$ form with import sequence). The same proteins were also associated with the monomeric $\mathrm{F}_{1} \mathrm{~F}_{\mathrm{O}^{-}}$ ATPase derived from $\rho^{0}$ cells [86]. It is still unknown whether $\mathrm{IF}_{1}-\mathrm{M} 1$ and $\mathrm{IF}_{1}-\mathrm{P}$ differ in the entry pathway to mitochondria or in ATP hydrolysis inhibition, but probably the specific association of $\mathrm{IF}_{1}-\mathrm{P}$ with the $\mathrm{F}_{1} \mathrm{~F}_{\mathrm{O}}$-ATPase could prevent dimerization [86]. Moreover, the active $\mathrm{IF}_{1}$ form (an antiparallel $\alpha$-helical coiled coil dimeric structure) in the matrix can associate with five $F_{1}$ subunits in different conformations [87]. The active $\mathrm{IF}_{1}$ is not essential for dimer formation [88,89], even if it can promote the $\mathrm{F}_{1} \mathrm{~F}_{\mathrm{O}}-\mathrm{ATPase}$ dimeric structure super-complexes [90]. The dimeric $\mathrm{IF}_{1}$ role is the ATPase inhibition by binding with a ratchet-like mechanism to the $\alpha / \beta_{\mathrm{DP}}$ site [91] proximal to the peripheral stalk [38]. However, some clues suggest that $\mathrm{IF}_{1}$ may also play a role in MPTP opening [92]. The active form of $\mathrm{IF}_{1}$ occurs at $\mathrm{pH}$ values below 6.5 [93], when the mitochondrial ATP hydrolysis to re-energize the IMM causes a disastrous ATP drop and cellular acidification. Interestingly, when $\mathrm{pH}$ lowers to 6.5 , the protonation of histidine residue(s) near the region of dimer combination shifts the $\mathrm{IF}_{1}$ equilibrium from tetramers (inactive $\mathrm{IF}_{1}$ form) to dimers (active $\mathrm{IF}_{1}$ form) so as to interact with $\mathrm{F}_{1}$ sector [93]. The reversible histidine(s) protonation on the mitochondrial matrix side [94] as well as the ospcHis ${ }^{12}$ protonation [49] are known to inhibit the MPTP. As a matter of fact, when the matrix $\mathrm{pH}$ decreases below 7.0, the MPTP is in the closed conformation. However, dithyl pyrocarbonate (DPC) allows MPTP opening at $\mathrm{pH} 6.5$ and maintains the $\mathrm{Ca}^{2+}$ dependent channel sensitivity to CsA. Accordingly, DPC reacts with histidyl residues and prevents their reversible protonation [94]. Therefore, at acidic $\mathrm{pHs} \mathrm{IF}_{1}$ is in the active form and the MPTP is closed. Conversely, at $\mathrm{pH}$ values $\geq 7.0$, the $\mathrm{IF}_{1}$ dimers aggregate into a tetramer which occludes the inhibitory portion of $\mathrm{F}_{1}$ sector [95]. At alkaline $\mathrm{pHs}$, to avoid detachment from the $\mathrm{F}_{1} \mathrm{~F}_{\mathrm{O}}$-ATPase under non-inhibitory conditions, the C-terminus of $\mathrm{IF}_{1}$ is kept anchored to $\mathrm{F}_{\mathrm{O}}[96,97]$, while the Nterminal region of $\mathrm{IF}_{1}$ is cross-linked to the $\alpha$ subunit [98]. In the presence of an incomplete structure of the peripheral stalk, the $\mathrm{Ca}^{2+}$-induced conformational change within $\mathrm{F}_{1}$ could be transmitted to the membrane subunits by the inactive form of $\mathrm{IF}_{1}$ [99]. Accordingly, $\mathrm{IF}_{1}$ by anchoring to the $\alpha$ subunit [98] and to a still unidentified membrane receptor of known molecular mass (approximately $M_{\mathrm{r}} 5400-6400 \mathrm{Da}$ ) [96] corresponding to one of the membrane subunits (A6L, 
$e, f, g$, DAPIT subunits and $6.8 \mathrm{kDa}$ proteolipid) [100], could create a low density bridge-like structure between the two monomers [32]. This connecting structure may be responsible for the conformational transmission and drive the conformational change from the $\mathrm{Ca}^{2+}$-bound catalytic subunits to the membrane subunits [99]. This transmission would draw up the dimer stalks and cause the reduction or even the loss of the membrane convexity between the two matched $F_{O}$ sectors [101]. Moreover, the MPTP inhibition at low osmotic strength is linked to changes in the IMM curvature [102]. Consistently, the pore formation between the two $\mathrm{F}_{1} \mathrm{~F}_{\mathrm{O}}$-ATPase monomers undoes the supra-molecular dimeric structure [57]. According to this model, the torque generation driven by ATP hydrolysis pushes the rotors of two adjacent $\mathrm{F}_{1} \mathrm{~F}_{\mathrm{O}}$-complexes towards opposite directions, allowing the respective monomer axis to contribute to reduce the distance between the two $F_{1}$ sectors from 15 to $10 \mathrm{~nm}$ [103]. The consequent curvature inversion of the cristae, associated with the spatial re-arrangement of the membrane subunits responsible for the "bridge shape domain", results in MPTP opening [104] (Fig. 4). Noteworthy, the rotation of the $\mathrm{Ca}^{2+}$ activated $\mathrm{F}_{1} \mathrm{~F}_{\mathrm{O}}$-ATPase [82], driven by ATP hydrolysis, can only occur in the presence of a correct structure of the $c$-ring or even in the absence of the $c$-ring. Accordingly, a proper $c$-ring or vestigial F-ATPases unable to build the $c$-ring preserve the MPTP properties [57,64]. Once transmitted through conformational changes, such rotation may be indirectly responsible for the stalk-to-stalk distance modification involved in MPTP opening. The supra-molecular arrangement of the $\mathrm{F}_{1} \mathrm{~F}_{\mathrm{O}^{-}}$ ATPase complexes is consistent with the ultrastructure of the cristae and with the ideal mitochondrial bioenergetics. When the $\mathrm{F}_{1} \mathrm{~F}_{\mathrm{O}}$-ATPase dimeric and oligomeric forms were destabilized by mutated $e$ subunits, the $\mathrm{F}_{1} \mathrm{~F}_{\mathrm{O}}$-ATPase activity was maintained, even if unexpectedly accompanied by IMM $\Delta \varphi$ reduction [105]. On the other hand the $e$ subunit overexpression, which supports the dimeric structure, was found to limit MPTP formation and prevent IMM depolarization [57].

To sum up, the experimental evidence accumulated up to now strongly suggests that MPTP formation and opening result from a multi-step process in which conformational changes play a key role. The data accumulated up to now are well compatible with a conformational mechanism triggered by the $\mathrm{Ca}^{2+}$-dependent $\mathrm{F}_{1} \mathrm{~F}_{\mathrm{O}}$ ATP hydrolysis, which implies a spatial rearrangement within $F_{1}$. According to the depicted model, this conformational change would constitute a structural signal that, once transduced to the membrane subunits, promotes the monomerization of $\mathrm{F}_{1} \mathrm{~F}_{\mathrm{O}}$-ATPase super-complexes and the curvature inversion at the apex of the cristae. So, the features of the $\mathrm{Ca}^{2+}$ activated $\mathrm{F}_{1} \mathrm{~F}_{\mathrm{O}}$-ATPase are fully consistent with the $\Delta \varphi$ loss and ATP hydrolysis, known as mitochondrial events which open the MPTP $[3,83]$.

\section{Acknowledgement}

This work was financed by the University of Bologna, RFO grant.

\section{References}

[1] D.G. Nicholls, S.J. Ferguson, 4 - The Chemiosmotic Proton Circuit in Isolated Organelles: Theory and Practice, in: Bioenerg. Fourth Ed., Academic Press, Boston, 2013: pp. 53-87. doi:10.1016/B978-0-12388425-1.00004-X.

[2] P. Mitchell, Keilin's respiratory chain concept and its chemiosmotic consequences, Science. 206 (1979) 1148-1159. 
[3] M. Zoratti, I. Szabò, The mitochondrial permeability transition, Biochim. Biophys. Acta. 1241 (1995) 139-176.

[4] I. Szabo, M. Zoratti, Mitochondrial channels: ion fluxes and more, Physiol. Rev. 94 (2014) 519-608. doi:10.1152/physrev.00021.2013.

[5] M.J. Pérez, R.A. Quintanilla, Development or disease: duality of the mitochondrial permeability transition pore, Dev. Biol. 426 (2017) 1-7. doi:10.1016/j.ydbio.2017.04.018.

[6] M.W. McEnery, A.M. Snowman, R.R. Trifiletti, S.H. Snyder, Isolation of the mitochondrial benzodiazepine receptor: association with the voltage-dependent anion channel and the adenine nucleotide carrier, Proc. Natl. Acad. Sci. U. S. A. 89 (1992) 3170-3174.

[7] K. Lê Quôc, D. Lê Quôc, Involvement of the ADP/ATP carrier in calcium-induced perturbations of the mitochondrial inner membrane permeability: importance of the orientation of the nucleotide binding site, Arch. Biochem. Biophys. 265 (1988) 249-257.

[8] N. Brustovetsky, M. Klingenberg, Mitochondrial ADP/ATP carrier can be reversibly converted into a large channel by Ca2+, Biochemistry (Mosc.). 35 (1996) 8483-8488. doi:10.1021/bi960833v.

[9] G. Beutner, A. Rück, B. Riede, D. Brdiczka, Complexes between porin, hexokinase, mitochondrial creatine kinase and adenylate translocator display properties of the permeability transition pore. Implication for regulation of permeability transition by the kinases, Biochim. Biophys. Acta. 1368 (1998) 7-18.

[10] A.W.C. Leung, P. Varanyuwatana, A.P. Halestrap, The mitochondrial phosphate carrier interacts with cyclophilin D and may play a key role in the permeability transition, J. Biol. Chem. 283 (2008) 2631226323. doi:10.1074/jbc.M805235200.

[11] M. Gutiérrez-Aguilar, D.L. Douglas, A.K. Gibson, T.L. Domeier, J.D. Molkentin, C.P. Baines, Genetic manipulation of the cardiac mitochondrial phosphate carrier does not affect permeability transition, J. Mol. Cell. Cardiol. 72 (2014) 316-325. doi:10.1016/j.yjmcc.2014.04.008.

[12] J.E. Kokoszka, K.G. Waymire, S.E. Levy, J.E. Sligh, J. Cai, D.P. Jones, G.R. MacGregor, D.C. Wallace, The ADP/ATP translocator is not essential for the mitochondrial permeability transition pore, Nature. 427 (2004) 461-465. doi:10.1038/nature02229.

[13] A. Krauskopf, O. Eriksson, W.J. Craigen, M.A. Forte, P. Bernardi, Properties of the permeability transition in VDAC1(-/-) mitochondria, Biochim. Biophys. Acta. 1757 (2006) 590-595. doi:10.1016/j.bbabio.2006.02.007.

[14] J. Šileikytè, E. Blachly-Dyson, R. Sewell, A. Carpi, R. Menabò, F. Di Lisa, F. Ricchelli, P. Bernardi, M. Forte, Regulation of the mitochondrial permeability transition pore by the outer membrane does not involve the peripheral benzodiazepine receptor (Translocator Protein of $18 \mathrm{kDa}$ (TSPO)), J. Biol. Chem. 289 (2014) 13769-13781. doi:10.1074/jbc.M114.549634.

[15] A.P. Halestrap, A.P. Richardson, The mitochondrial permeability transition: a current perspective on its identity and role in ischaemia/reperfusion injury, J. Mol. Cell. Cardiol. 78 (2015) 129-141. doi:10.1016/j.yjmcc.2014.08.018.

[16] G. Beutner, R.E. Alanzalon, G.A. Porter, Cyclophilin D regulates the dynamic assembly of mitochondrial ATP synthase into synthasomes, Sci. Rep. 7 (2017) 14488. doi:10.1038/s41598-01714795-x.

[17] P.D. Boyer, The ATP synthase--a splendid molecular machine, Annu. Rev. Biochem. 66 (1997) 717749. doi:10.1146/annurev.biochem.66.1.717.

[18] M. Bonora, A. Bononi, E. De Marchi, C. Giorgi, M. Lebiedzinska, S. Marchi, S. Patergnani, A. Rimessi, J.M. Suski, A. Wojtala, M.R. Wieckowski, G. Kroemer, L. Galluzzi, P. Pinton, Role of the c subunit of the FO ATP synthase in mitochondrial permeability transition, Cell Cycle. 12 (2013) 674-683. doi:10.4161/cc.23599.

[19] V. Giorgio, S. von Stockum, M. Antoniel, A. Fabbro, F. Fogolari, M. Forte, G.D. Glick, V. Petronilli, M. Zoratti, I. Szabó, G. Lippe, P. Bernardi, Dimers of mitochondrial ATP synthase form the permeability transition pore, Proc. Natl. Acad. Sci. U. S. A. 110 (2013) 5887-5892. doi:10.1073/pnas.1217823110.

[20] S. Nesci, F. Trombetti, V. Ventrella, A. Pagliarani, The c-Ring of the F1FO-ATP Synthase: Facts and Perspectives, J. Membr. Biol. 249 (2016) 11-21. doi:10.1007/s00232-015-9860-3.

[21] D.G. Nicholls, S.J. Ferguson, 7 - ATP Synthases and Bacterial Flagella Rotary Motors, in: Bioenerg. Fourth Ed., Academic Press, Boston, 2013: pp. 197-220. doi:10.1016/B978-0-12-388425-1.00007-5. 
[22] W. Junge, N. Nelson, ATP synthase, Annu. Rev. Biochem. 84 (2015) 631-657. doi:10.1146/annurevbiochem-060614-034124.

[23] C. von Ballmoos, A. Wiedenmann, P. Dimroth, Essentials for ATP synthesis by F1F0 ATP synthases, Annu. Rev. Biochem. 78 (2009) 649-672. doi:10.1146/annurev.biochem.78.081307.104803.

[24] P. Dimroth, C. von Ballmoos, T. Meier, Catalytic and mechanical cycles in F-ATP synthases. Fourth in the Cycles Review Series, EMBO Rep. 7 (2006) 276-282. doi:10.1038/sj.embor.7400646.

[25] C. von Ballmoos, G.M. Cook, P. Dimroth, Unique rotary ATP synthase and its biological diversity, Annu. Rev. Biophys. 37 (2008) 43-64. doi:10.1146/annurev.biophys.37.032807.130018.

[26] S. Nesci, V. Ventrella, F. Trombetti, M. Pirini, A. Pagliarani, Mussel and mammalian ATP synthase share the same bioenergetic cost of ATP, J. Bioenerg. Biomembr. 45 (2013) 289-300. doi:10.1007/s10863-013-9504-1.

[27] C. Gibbons, M.G. Montgomery, A.G. Leslie, J.E. Walker, The structure of the central stalk in bovine F(1)-ATPase at 2.4 A resolution, Nat. Struct. Biol. 7 (2000) 1055-1061. doi:10.1038/80981.

[28] R.J. Devenish, M. Prescott, G.M. Boyle, P. Nagley, The Oligomycin Axis of Mitochondrial ATP Synthase: OSCP and the Proton Channel, J. Bioenerg. Biomembr. 32 (2000) 507-515. doi:10.1023/A:1005621125812.

[29] W.D. Frasch, The participation of metals in the mechanism of the F(1)-ATPase, Biochim. Biophys. Acta. 1458 (2000) 310-325.

[30] S. Nesci, F. Trombetti, V. Ventrella, A. Pagliarani, Post-translational modifications of the mitochondrial F1FO-ATPase, Biochim. Biophys. Acta. 1861 (2017) 2902-2912. doi:10.1016/j.bbagen.2017.08.007.

[31] H. Guo, S.A. Bueler, J.L. Rubinstein, Atomic model for the dimeric FO region of mitochondrial ATP synthase, Science. 358 (2017) 936-940. doi:10.1126/science.aao4815.

[32] F. Minauro-Sanmiguel, S. Wilkens, J.J. García, Structure of dimeric mitochondrial ATP synthase: novel F0 bridging features and the structural basis of mitochondrial cristae biogenesis, Proc. Natl. Acad. Sci. U. S. A. 102 (2005) 12356-12358. doi:10.1073/pnas.0503893102.

[33] I. Arnold, K. Pfeiffer, W. Neupert, R.A. Stuart, H. Schägger, Yeast mitochondrial F1FO-ATP synthase exists as a dimer: identification of three dimer-specific subunits, EMBO J. 17 (1998) 7170-7178. doi:10.1093/emboj/17.24.7170.

[34] M. Strauss, G. Hofhaus, R.R. Schröder, W. Kühlbrandt, Dimer ribbons of ATP synthase shape the inner mitochondrial membrane, EMBO J. 27 (2008) 1154-1160. doi:10.1038/emboj.2008.35.

[35] K.M. Davies, C. Anselmi, I. Wittig, J.D. Faraldo-Gómez, W. Kühlbrandt, Structure of the yeast F1FoATP synthase dimer and its role in shaping the mitochondrial cristae, Proc. Natl. Acad. Sci. U. S. A. 109 (2012) 13602-13607. doi:10.1073/pnas.1204593109.

[36] K.M. Davies, M. Strauss, B. Daum, J.H. Kief, H.D. Osiewacz, A. Rycovska, V. Zickermann, W. Kühlbrandt, Macromolecular organization of ATP synthase and complex I in whole mitochondria, Proc. Natl. Acad. Sci. U. S. A. 108 (2011) 14121-14126. doi:10.1073/pnas.1103621108.

[37] P. Paumard, J. Vaillier, B. Coulary, J. Schaeffer, V. Soubannier, D.M. Mueller, D. Brèthes, J.-P. di Rago, J. Velours, The ATP synthase is involved in generating mitochondrial cristae morphology, EMBO J. 21 (2002) 221-230. doi:10.1093/emboj/21.3.221.

[38] A. Hahn, K. Parey, M. Bublitz, D.J. Mills, V. Zickermann, J. Vonck, W. Kühlbrandt, T. Meier, Structure of a Complete ATP Synthase Dimer Reveals the Molecular Basis of Inner Mitochondrial Membrane Morphology, Mol. Cell. 63 (2016) 445-456. doi:10.1016/j.molcel.2016.05.037.

[39] P. Bernardi, F. Di Lisa, F. Fogolari, G. Lippe, From ATP to PTP and Back: A Dual Function for the Mitochondrial ATP Synthase, Circ. Res. 116 (2015) 1850-1862. doi:10.1161/CIRCRESAHA.115.306557.

[40] K.W. Kinnally, B. Antonsson, A tale of two mitochondrial channels, MAC and PTP, in apoptosis, Apoptosis Int. J. Program. Cell Death. 12 (2007) 857-868. doi:10.1007/s10495-007-0722-z.

[41] I. Szabó, P. Bernardi, M. Zoratti, Modulation of the mitochondrial megachannel by divalent cations and protons, J. Biol. Chem. 267 (1992) 2940-2946.

[42] V. Izzo, J.M. Bravo-San Pedro, V. Sica, G. Kroemer, L. Galluzzi, Mitochondrial Permeability Transition: New Findings and Persisting Uncertainties, Trends Cell Biol. 26 (2016) 655-667. doi:10.1016/j.tcb.2016.04.006. 
[43] A. Rasola, P. Bernardi, Mitochondrial permeability transition in $\mathrm{Ca}(2+)$-dependent apoptosis and necrosis, Cell Calcium. 50 (2011) 222-233. doi:10.1016/j.ceca.2011.04.007.

[44] P. Bernardi, A. Rasola, M. Forte, G. Lippe, The Mitochondrial Permeability Transition Pore: Channel Formation by F-ATP Synthase, Integration in Signal Transduction, and Role in Pathophysiology, Physiol. Rev. 95 (2015) 1111-1155. doi:10.1152/physrev.00001.2015.

[45] C.P. Baines, R.A. Kaiser, N.H. Purcell, N.S. Blair, H. Osinska, M.A. Hambleton, E.W. Brunskill, M.R. Sayen, R.A. Gottlieb, G.W. Dorn, J. Robbins, J.D. Molkentin, Loss of cyclophilin D reveals a critical role for mitochondrial permeability transition in cell death, Nature. 434 (2005) 658-662. doi:10.1038/nature03434.

[46] A.P. Halestrap, C.P. Connern, E.J. Griffiths, P.M. Kerr, Cyclosporin A binding to mitochondrial cyclophilin inhibits the permeability transition pore and protects hearts from ischaemia/reperfusion injury, Mol. Cell. Biochem. 174 (1997) 167-172.

[47] V. Giorgio, E. Bisetto, M.E. Soriano, F. Dabbeni-Sala, E. Basso, V. Petronilli, M.A. Forte, P. Bernardi, G. Lippe, Cyclophilin D modulates mitochondrial FOF1-ATP synthase by interacting with the lateral stalk of the complex, J. Biol. Chem. 284 (2009) 33982-33988. doi:10.1074/jbc.M109.020115.

[48] J. He, J. Carroll, S. Ding, I.M. Fearnley, J.E. Walker, Permeability transition in human mitochondria persists in the absence of peripheral stalk subunits of ATP synthase, Proc. Natl. Acad. Sci. U. S. A. 114 (2017) 9086-9091. doi:10.1073/pnas.1711201114.

[49] M. Antoniel, K. Jones, S. Antonucci, B. Spolaore, F. Fogolari, V. Petronilli, V. Giorgio, M. Carraro, F. Di Lisa, M. Forte, I. Szabó, G. Lippe, P. Bernardi, The unique histidine in OSCP subunit of F-ATP synthase mediates inhibition of the permeability transition pore by acidic pH, EMBO Rep. (2017). doi:10.15252/embr.201744705.

[50] P. Bernardi, G. Lippe, Channel Formation by F-ATP Synthase and the Permeability Transition Pore: An Update, Curr. Opin. Physiol. 3 (2018) 1-5. doi:10.1016/j.cophys.2017.12.006.

[51] E. Pavlov, E. Zakharian, C. Bladen, C.T.M. Diao, C. Grimbly, R.N. Reusch, R.J. French, A large, voltagedependent channel, isolated from mitochondria by water-free chloroform extraction, Biophys. J. 88 (2005) 2614-2625. doi:10.1529/biophysj.104.057281.

[52] K.N. Alavian, G. Beutner, E. Lazrove, S. Sacchetti, H.-A. Park, P. Licznerski, H. Li, P. Nabili, K. Hockensmith, M. Graham, G.A. Porter, E.A. Jonas, An uncoupling channel within the c-subunit ring of the F1FO ATP synthase is the mitochondrial permeability transition pore, Proc. Natl. Acad. Sci. U. S. A. 111 (2014) 10580-10585. doi:10.1073/pnas.1401591111.

[53] J.E. McGeoch, M.W. McGeoch, R. Mao, G. Guidotti, Opposing actions of cGMP and calcium on the conductance of the $F(0)$ subunit c pore, Biochem. Biophys. Res. Commun. 274 (2000) 835-840. doi:10.1006/bbrc.2000.3231.

[54] J.E. McGeoch, G. Guidotti, A $0.1-700 \mathrm{~Hz}$ current through a voltage-clamped pore: candidate protein for initiator of neural oscillations, Brain Res. 766 (1997) 188-194.

[55] I. Szabó, M. Zoratti, The mitochondrial megachannel is the permeability transition pore, J. Bioenerg. Biomembr. 24 (1992) 111-117.

[56] T.S. Azarashvili, J. Tyynelä, I.V. Odinokova, P.A. Grigorjev, M. Baumann, Y.V. Evtodienko, N.-E.L. Saris, Phosphorylation of a peptide related to subunit c of the F0F1-ATPase/ATP synthase and relationship to permeability transition pore opening in mitochondria, J. Bioenerg. Biomembr. 34 (2002) 279-284.

[57] M. Bonora, C. Morganti, G. Morciano, G. Pedriali, M. Lebiedzinska-Arciszewska, G. Aquila, C. Giorgi, P. Rizzo, G. Campo, R. Ferrari, G. Kroemer, M.R. Wieckowski, L. Galluzzi, P. Pinton, Mitochondrial permeability transition involves dissociation of F1FO ATP synthase dimers and C-ring conformation, EMBO Rep. 18 (2017) 1077-1089. doi:10.15252/embr.201643602.

[58] P.A. Elustondo, M. Nichols, A. Negoda, A. Thirumaran, E. Zakharian, G.S. Robertson, E.V. Pavlov, Mitochondrial permeability transition pore induction is linked to formation of the complex of ATPase C-subunit, polyhydroxybutyrate and inorganic polyphosphate, Cell Death Discov. 2 (2016) 16070. doi:10.1038/cddiscovery.2016.70.

[59] W. Zhou, F. Marinelli, C. Nief, J.D. Faraldo-Gómez, Atomistic simulations indicate the c-subunit ring of the F1Fo ATP synthase is not the mitochondrial permeability transition pore, ELife. 6 (2017) e23781. doi:10.7554/eLife.23781. 
[60] B. Oberfeld, J. Brunner, P. Dimroth, Phospholipids occupy the internal lumen of the $c$ ring of the ATP synthase of Escherichia coli, Biochemistry (Mosc.). 45 (2006) 1841-1851. doi:10.1021/bi052304+.

[61] U. De Marchi, E. Basso, I. Szabò, M. Zoratti, Electrophysiological characterization of the Cyclophilin D-deleted mitochondrial permeability transition pore, Mol. Membr. Biol. 23 (2006) 521-530. doi:10.1080/09687860600907644.

[62] T. Nakagawa, S. Shimizu, T. Watanabe, O. Yamaguchi, K. Otsu, H. Yamagata, H. Inohara, T. Kubo, Y. Tsujimoto, Cyclophilin D-dependent mitochondrial permeability transition regulates some necrotic but not apoptotic cell death, Nature. 434 (2005) 652-658. doi:10.1038/nature03317.

[63] J.P. Abrahams, A.G. Leslie, R. Lutter, J.E. Walker, Structure at 2.8 A resolution of F1-ATPase from bovine heart mitochondria, Nature. 370 (1994) 621-628. doi:10.1038/370621a0.

[64] J. He, H.C. Ford, J. Carroll, S. Ding, I.M. Fearnley, J.E. Walker, Persistence of the mitochondrial permeability transition in the absence of subunit c of human ATP synthase, Proc. Natl. Acad. Sci. U. S. A. 114 (2017) 3409-3414. doi:10.1073/pnas.1702357114.

[65] L. He, J.J. Lemasters, Regulated and unregulated mitochondrial permeability transition pores: a new paradigm of pore structure and function?, FEBS Lett. 512 (2002) 1-7.

[66] V. Giorgio, L. Guo, C. Bassot, V. Petronilli, P. Bernardi, Calcium and regulation of the mitochondrial permeability transition, Cell Calcium. (2017). doi:10.1016/j.ceca.2017.05.004.

[67] D.M. Rees, M.G. Montgomery, A.G.W. Leslie, J.E. Walker, Structural evidence of a new catalytic intermediate in the pathway of ATP hydrolysis by F1-ATPase from bovine heart mitochondria, Proc. Natl. Acad. Sci. U. S. A. 109 (2012) 11139-11143. doi:10.1073/pnas.1207587109.

[68] P.L. Pedersen, N. Williams, J. Hullihen, Mitochondrial ATP synthase: dramatic Mg2+-induced alterations in the structure and function of the F1-ATPase moiety, Biochemistry (Mosc.). 26 (1987) 8631-8637.

[69] L. Nathanson, Z. Gromet-Elhanan, Mutations in the $\beta$-subunit Thr159 and Glu184 of the Rhodospirillum rubrum FOF1 ATP synthase reveal differences in ligands for the coupled Mg2+- and decoupled Ca2+-dependent FOF1 activities, J. Biol. Chem. 275 (2000) 901-905. doi:10.1074/jbc.275.2.901.

[70] V. Giorgio, V. Burchell, M. Schiavone, C. Bassot, G. Minervini, V. Petronilli, F. Argenton, M. Forte, S. Tosatto, G. Lippe, P. Bernardi, $\mathrm{Ca}(2+)$ binding to F-ATP synthase $\beta$ subunit triggers the mitochondrial permeability transition, EMBO Rep. 18 (2017) 1065-1076. doi:10.15252/embr.201643354.

[71] V.K. Dickson, J.A. Silvester, I.M. Fearnley, A.G.W. Leslie, J.E. Walker, On the structure of the stator of the mitochondrial ATP synthase, EMBO J. 25 (2006) 2911-2918. doi:10.1038/sj.emboj.7601177.

[72] G. Arselin, M.-F. Giraud, A. Dautant, J. Vaillier, D. Brèthes, B. Coulary-Salin, J. Schaeffer, J. Velours, The GxxxG motif of the transmembrane domain of subunit e is involved in the dimerization/oligomerization of the yeast ATP synthase complex in the mitochondrial membrane, Eur. J. Biochem. 270 (2003) 1875-1884.

[73] S. Brunner, V. Everard-Gigot, R.A. Stuart, Su e of the yeast F1Fo-ATP synthase forms homodimers, J. Biol. Chem. 277 (2002) 48484-48489. doi:10.1074/jbc.M209382200.

[74] S. Nesci, Mitochondrial permeability transition, $F_{1} F_{0}$-ATPase and calcium: an enigmatic triangle, EMBO Rep. 18 (2017) 1265-1267. doi:10.15252/embr.201744570.

[75] S. Nesci, F. Trombetti, V. Ventrella, M. Pirini, A. Pagliarani, Kinetic properties of the mitochondrial F1FO-ATPase activity elicited by $\mathrm{Ca}(2+)$ in replacement of $\mathrm{Mg}(2+)$, Biochimie. 140 (2017) 73-81. doi:10.1016/j.biochi.2017.06.013.

[76] Z. Gromet-Elhanan, S. Weiss, Regulation of .DELTA. .mu.H + -coupled ATP synthesis and hydrolysis: role of divalent cations and of the FOF1-.beta. subunit, Biochemistry (Mosc.). 28 (1989) 3645-3650. doi:10.1021/bi00435a004.

[77] S. Papageorgiou, A.B. Melandri, G. Solaini, Relevance of divalent cations to ATP-driven proton pumping in beef heart mitochondrial F0F1-ATPase, J. Bioenerg. Biomembr. 30 (1998) 533-541.

[78] U. Pick, M. Weiss, A light-dependent dicyclohexylcarbodiimide-sensitive Ca-ATPase activity in chloroplasts which is not coupled to proton translocation, Eur. J. Biochem. 173 (1988) 623-628.

[79] S. Nesci, V. Ventrella, F. Trombetti, M. Pirini, A. Pagliarani, Preferential nitrite inhibition of the mitochondrial F1FO-ATPase activities when activated by $\mathrm{Ca}(2+)$ in replacement of the natural cofactor Mg(2+), Biochim. Biophys. Acta. 1860 (2016) 345-353. doi:10.1016/j.bbagen.2015.11.004. 
[80] S. Nesci, F. Trombetti, V. Ventrella, M. Pirini, A. Pagliarani, The inhibition of the mitochondrial F1FOATPase activity when activated by Ca2+ opens new regulatory roles for NAD, Biol. Chem. 399 (2018) 197-202. doi:10.1515/hsz-2017-0209.

[81] R. Casadio, B.A. Melandri, CaATP inhibition of the MgATP-dependent proton pump (H+-ATPase) in bacterial photosynthetic membranes with a mechanism of alternative substrate inhibition, J. Biol. Inorg. Chem. 1 (1996) 284-291.

[82] W.C. Tucker, A. Schwarz, T. Levine, Z. Du, Z. Gromet-Elhanan, M.L. Richter, G. Haran, Observation of calcium-dependent unidirectional rotational motion in recombinant photosynthetic F1-ATPase molecules, J. Biol. Chem. 279 (2004) 47415-47418. doi:10.1074/jbc.C400269200.

[83] S. Nesci, The mitochondrial permeability transition and the connection between F1FO-ATPase and calcium, Curr. Sci. 113 (2017) 1820-1821.

[84] C. Jiko, K.M. Davies, K. Shinzawa-Itoh, K. Tani, S. Maeda, D.J. Mills, T. Tsukihara, Y. Fujiyoshi, W. Kühlbrandt, C. Gerle, Bovine F1Fo ATP synthase monomers bend the lipid bilayer in 2D membrane crystals, ELife. 4 (2015) e06119. doi:10.7554/eLife.06119.

[85] A. Zhou, A. Rohou, D.G. Schep, J.V. Bason, M.G. Montgomery, J.E. Walker, N. Grigorieff, J.L. Rubinstein, Structure and conformational states of the bovine mitochondrial ATP synthase by cryoEM, ELife. 4 (2015) e10180. doi:10.7554/eLife.10180.

[86] I. Wittig, B. Meyer, H. Heide, M. Steger, L. Bleier, Z. Wumaier, M. Karas, H. Schägger, Assembly and oligomerization of human ATP synthase lacking mitochondrial subunits a and A6L, Biochim. Biophys. Acta. 1797 (2010) 1004-1011. doi:10.1016/j.bbabio.2010.02.021.

[87] J.V. Bason, M.G. Montgomery, A.G.W. Leslie, J.E. Walker, Pathway of binding of the intrinsically disordered mitochondrial inhibitor protein to F1-ATPase, Proc. Natl. Acad. Sci. U. S. A. 111 (2014) 11305-11310. doi:10.1073/pnas.1411560111.

[88] M. Dienhart, K. Pfeiffer, H. Schagger, R.A. Stuart, Formation of the yeast F1F0-ATP synthase dimeric complex does not require the ATPase inhibitor protein, Inh1, J. Biol. Chem. 277 (2002) 39289-39295. doi:10.1074/jbc.M205720200.

[89] L. Tomasetig, F. Di Pancrazio, D.A. Harris, I. Mavelli, G. Lippe, Dimerization of F0F1ATP synthase from bovine heart is independent from the binding of the inhibitor protein IF1, Biochim. Biophys. Acta. 1556 (2002) 133-141.

[90] J.J. García, E. Morales-Ríos, P. Cortés-Hernandez, J.S. Rodríguez-Zavala, The inhibitor protein (IF1) promotes dimerization of the mitochondrial F1F0-ATP synthase, Biochemistry (Mosc.). 45 (2006) 12695-12703. doi:10.1021/bi060339j.

[91] J.R. Gledhill, M.G. Montgomery, A.G.W. Leslie, J.E. Walker, How the regulatory protein, IF(1), inhibits F(1)-ATPase from bovine mitochondria, Proc. Natl. Acad. Sci. U. S. A. 104 (2007) 15671-15676. doi:10.1073/pnas.0707326104.

[92] D. Faccenda, C.H. Tan, A. Seraphim, M.R. Duchen, M. Campanella, IF1 limits the apoptotic-signalling cascade by preventing mitochondrial remodelling, Cell Death Differ. 20 (2013) 686-697. doi:10.1038/cdd.2012.163.

[93] E. Cabezon, P.J. Butler, M.J. Runswick, J.E. Walker, Modulation of the oligomerization state of the bovine F1-ATPase inhibitor protein, IF1, by pH, J. Biol. Chem. 275 (2000) 25460-25464. doi:10.1074/jbc.M003859200.

[94] A. Nicolli, V. Petronilli, P. Bernardi, Modulation of the mitochondrial cyclosporin A-sensitive permeability transition pore by matrix $\mathrm{pH}$. Evidence that the pore open-closed probability is regulated by reversible histidine protonation, Biochemistry (Mosc.). 32 (1993) 4461-4465.

[95] E. Cabezón, M.J. Runswick, A.G. Leslie, J.E. Walker, The structure of bovine IF(1), the regulatory subunit of mitochondrial F-ATPase, EMBO J. 20 (2001) 6990-6996. doi:10.1093/emboj/20.24.6990.

[96] C. Lopez-Mediavilla, H. Vigny, C. Godinot, Docking the mitochondrial inhibitor protein IF1 to a membrane receptor different from the F1-ATPase beta subunit, Eur. J. Biochem. 215 (1993) 487496.

[97] F. Zanotti, G. Raho, A. Gaballo, S. Papa, Inhibitory and anchoring domains in the ATPase inhibitor protein IF1 of bovine heart mitochondrial ATP synthase, J. Bioenerg. Biomembr. 36 (2004) 447-457. doi:10.1023/B:JOBB.0000047327.68173.9b. 
[98] F. Minauro-Sanmiguel, C. Bravo, J.J. García, Cross-linking of the endogenous inhibitor protein (IF1) with rotor (gamma, epsilon) and stator (alpha) subunits of the mitochondrial ATP synthase, J. Bioenerg. Biomembr. 34 (2002) 433-443.

[99] S. Nesci, New insight in a new entity: the mitochondrial permeability transition pore arises from the Ca2+-activated F1FO-ATPases, Sci. Bull. (2018). doi:10.1016/j.scib.2017.12.019.

[100] M.J. Runswick, J.V. Bason, M.G. Montgomery, G.C. Robinson, I.M. Fearnley, J.E. Walker, The affinity purification and characterization of ATP synthase complexes from mitochondria, Open Biol. 3 (2013) 120160. doi:10.1098/rsob.120160.

[101] B. Daum, A. Walter, A. Horst, H.D. Osiewacz, W. Kühlbrandt, Age-dependent dissociation of ATP synthase dimers and loss of inner-membrane cristae in mitochondria, Proc. Natl. Acad. Sci. U. S. A. 110 (2013) 15301-15306. doi:10.1073/pnas.1305462110.

[102] A.Y. Baev, P.A. Elustondo, A. Negoda, E.V. Pavlov, Osmotic regulation of the mitochondrial permeability transition pore investigated by light scattering, fluorescence and electron microscopy techniques, Anal. Biochem. (2017). doi:10.1016/j.ab.2017.07.006.

[103] N. Buzhynskyy, P. Sens, V. Prima, J.N. Sturgis, S. Scheuring, Rows of ATP synthase dimers in native mitochondrial inner membranes, Biophys. J. 93 (2007) 2870-2876. doi:10.1529/biophysj.107.109728.

[104] S. Nesci, A Lethal Channel between the ATP Synthase Monomers, Trends Biochem. Sci. (2018). doi:10.1016/j.tibs.2018.02.013.

[105] C. Bornhövd, F. Vogel, W. Neupert, A.S. Reichert, Mitochondrial membrane potential is dependent on the oligomeric state of F1F0-ATP synthase supracomplexes, J. Biol. Chem. 281 (2006) 1399013998. doi:10.1074/jbc.M512334200. 


\section{Captions to Figures}

Figure 1. Subunit composition and structural arrangement of the $\mathrm{F}_{1} \mathrm{~F}_{\mathrm{O}}-\mathrm{ATPase}$ monomer. Protein subunits are drawn as ribbon representations (modified PDB ID codes: 5ARA and 6B2Z). Olive, $\alpha$ subunits; red, $\beta$ subunits; blue, $\gamma$ subunit; fuchsia, $\delta$ subunit; turquoise, $\varepsilon$ subunit; orange, ring of $c$ subunits; violet, $a$ subunit; purple, A6L subunit; gold, $f$ subunit; green, $b$ subunit; pink, $d$ subunit; sky-blue, $\mathrm{F}_{6}$ subunit; grey, OSCP subunit. $e$ and $g$ subunit drawn in ball and stick mode, are blue and light blue, respectively. DAPIT and the $6.8 \mathrm{kDa}$ proteolipid, still undefined membrane subunits, are not represented.

Figure 2. Detailed representation of the $\mathrm{F}_{1} \mathrm{~F}_{\mathrm{O}}$-ATPase subunits involved in catalysis. a) The OSCP subunit (grey) and the $\beta$ subunit (red) with the "long connecting loop" and the "crown region" highlighted in olive and blue, respectively. The CaATP substrate in the catalytic binding site is depicted as ball and stick model (modified PDB ID code: 5ARA). The cofactors $\mathrm{Mg}^{2+}$ (yellow) (b) and $\mathrm{Ca}^{2+}$ (c) (turquoise) are depicted as inserted spheres in the $\beta_{\mathrm{TP}}$ site (modified PDB ID code:2JDI). ATP molecule and the side chains of $\mathrm{Thr}^{163}, \mathrm{Glu}^{192}, \mathrm{Asp}^{256}, \mathrm{Arg}^{189}$ are drawn as ball and stick models.

Figure 3. Putative involvement of the $\mathrm{Ca}^{2+}$-activated $\mathrm{F}_{1} \mathrm{~F}_{\mathrm{O}}$-ATPase complex(es) in MPTP formation. A) The dimeric form of the $\mathrm{Mg}^{2+}$-activated $\mathrm{F}_{1} \mathrm{~F}_{\mathrm{O}}$-ATPase super-complex is associated with a highly convex membrane curvature which protrudes into the matrix; $\mathrm{B}$ ) the dissociation of the $\mathrm{F}_{1} \mathrm{~F}_{\mathrm{O}^{-}}$ ATPase dimers, produced by the mechanical signal transduction from the $\mathrm{Ca}^{2+}$-activated $\mathrm{F}_{1}$ sector to the $\mathrm{F}_{\mathrm{O}}$ sector (as detailed in the text), reduces the membrane curvature at the apex of the cristae. By this mechanism, the channel forms between two adjacent monomers. (Modified PDB ID codes: 5ARA and 6B2Z).

Figure 4. $\mathrm{F}_{\mathrm{O}}$ dimerization and IMM curvature change as related events. The membrane dimeric domain is formed by the membrane-intrinsic $\alpha$-helices of $b$ subunit, the $a$ subunit, the A6L subunit, the $f$ subunit, the $e$ subunit and the $g$ subunit of each monomer. According to the model, the reduction of the concave IMM curvature dissociates the membrane-embedded $\mathrm{F}_{\mathrm{O}}$ dimer and creates a pore at the monomer-monomer interface. Color subunits are the same as in Figure 1. (Modified PDB ID code: 6B2Z). 

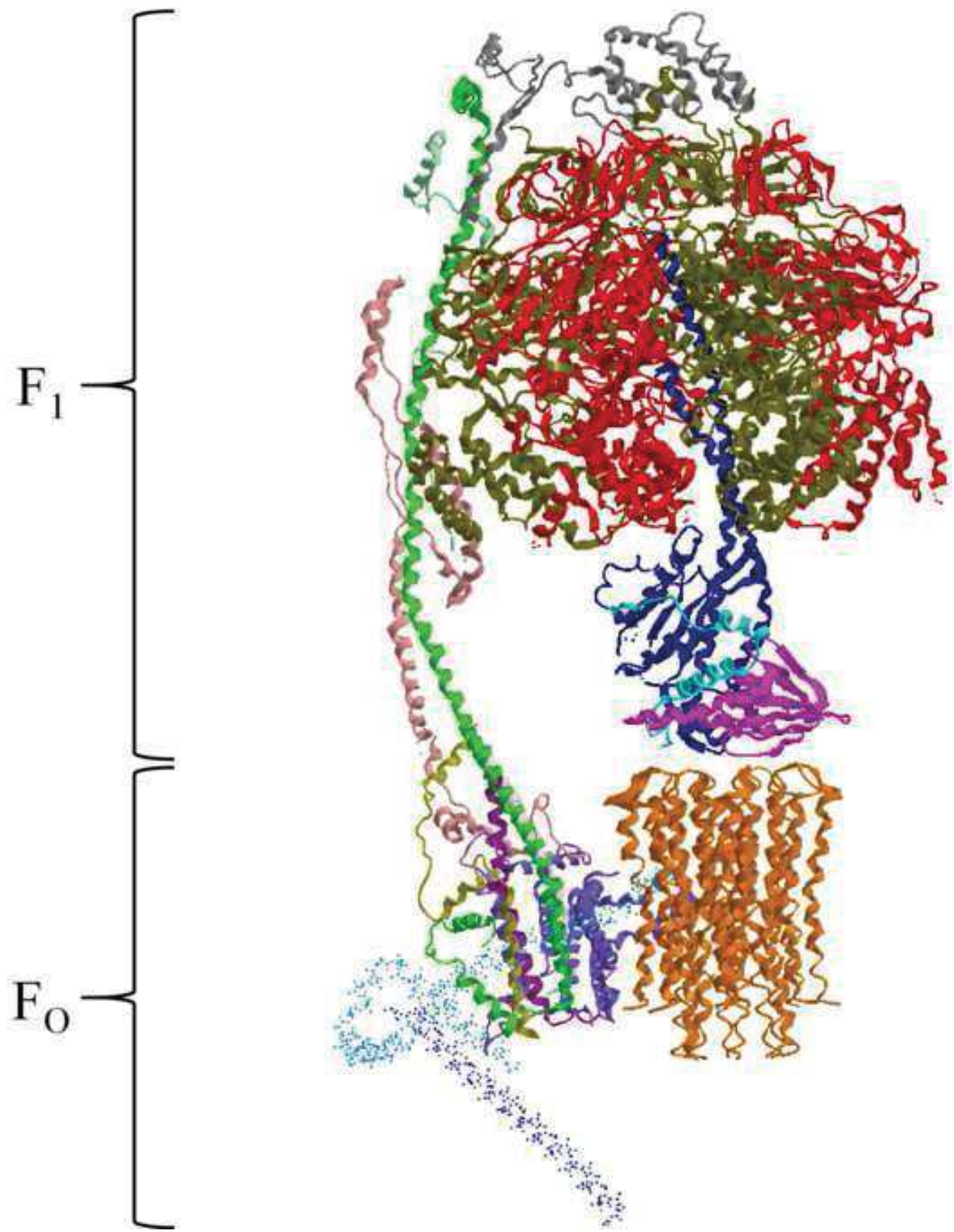
Figure 2

Click here to download high resolution image

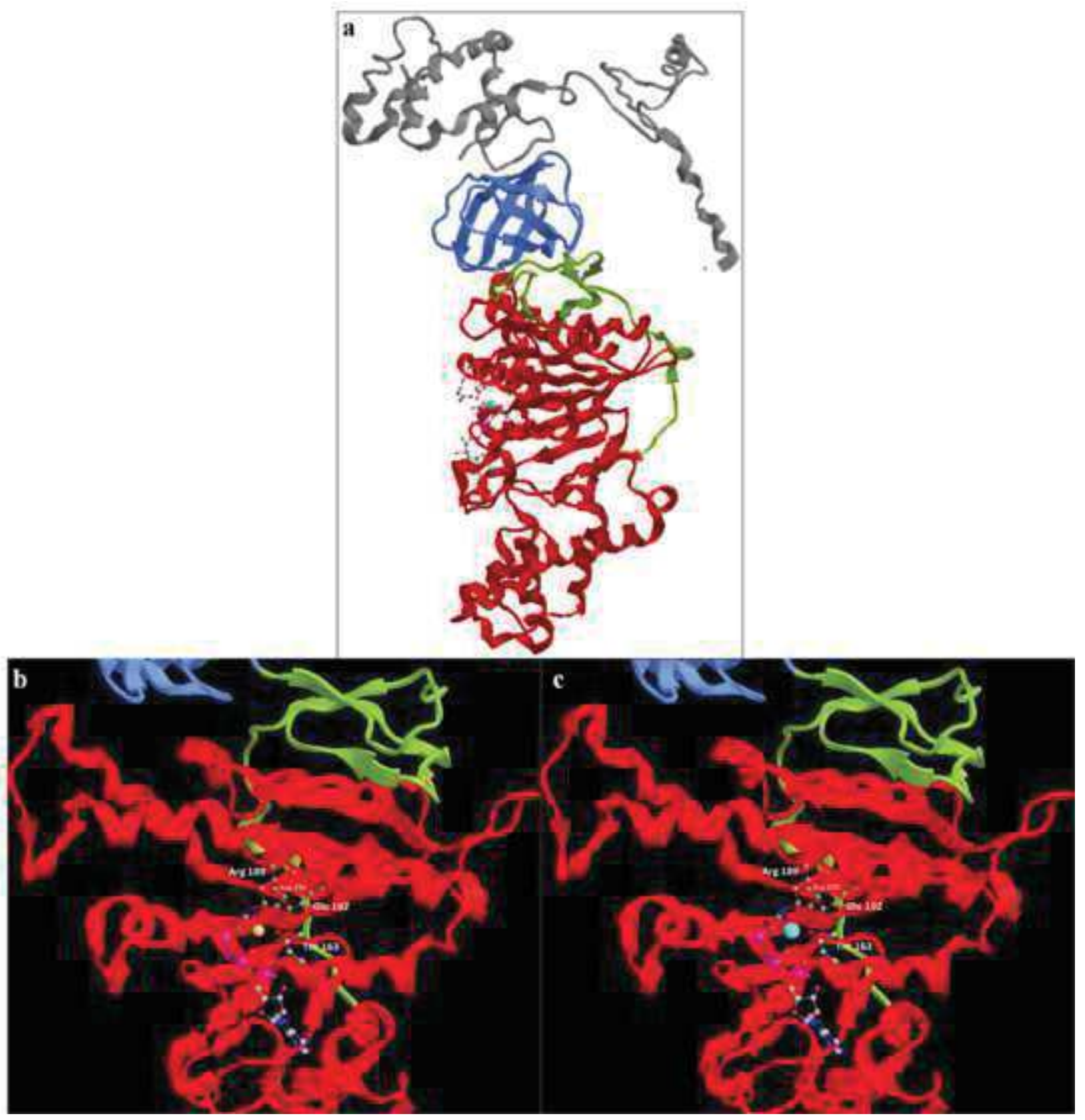


A)
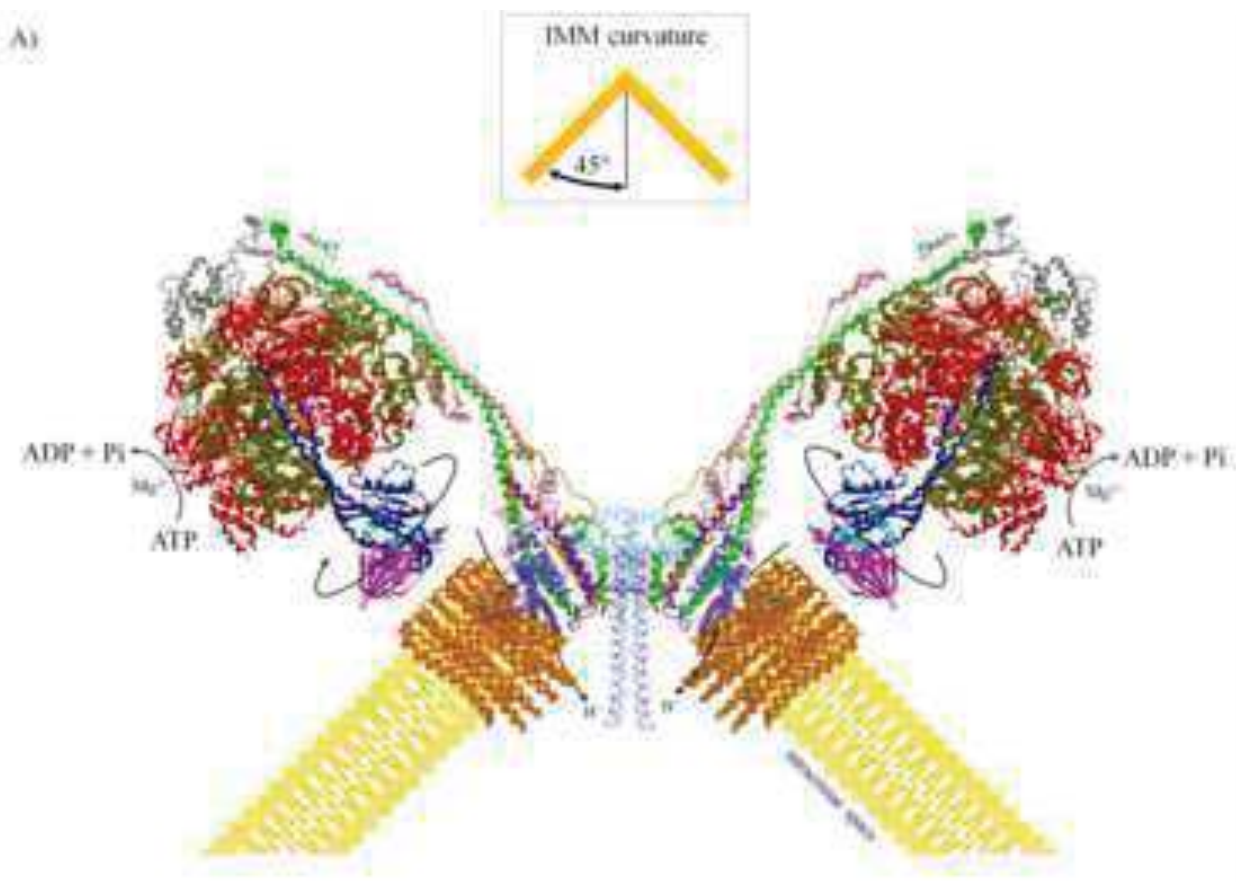

B)

IMM Curvature
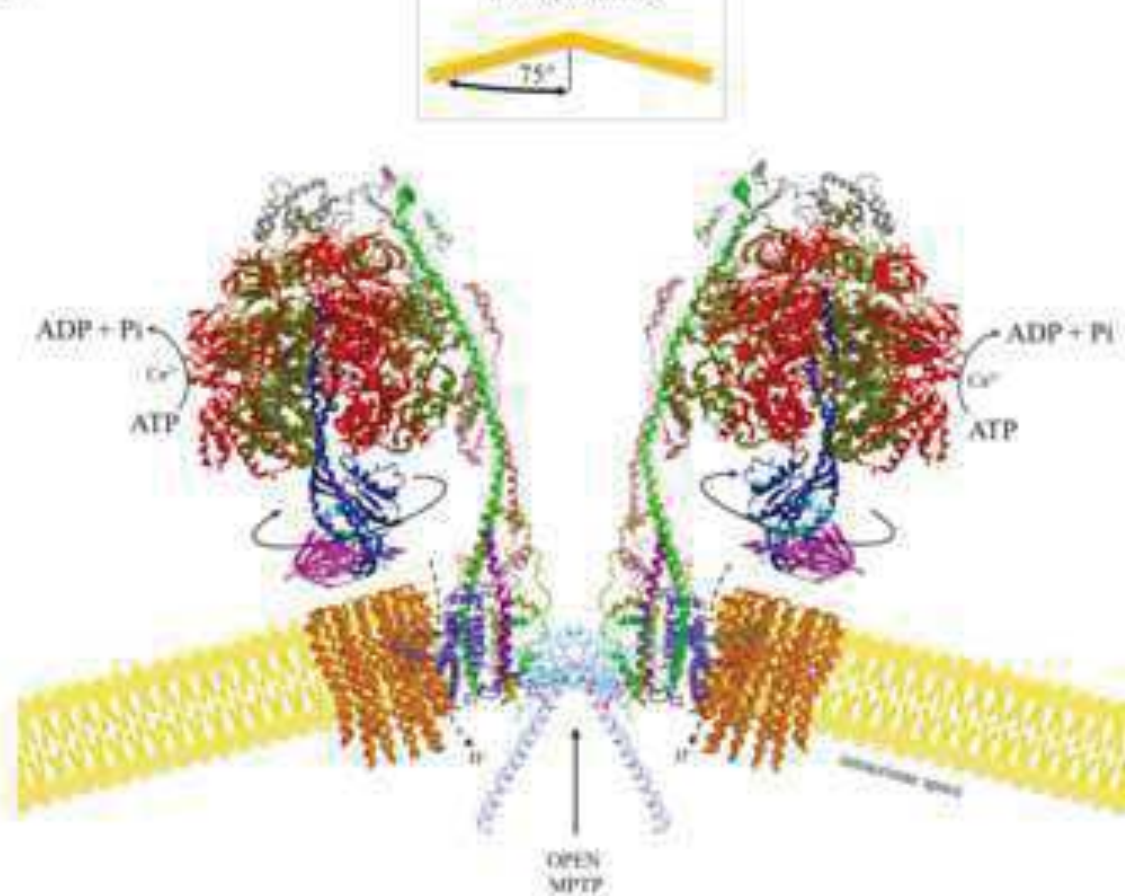

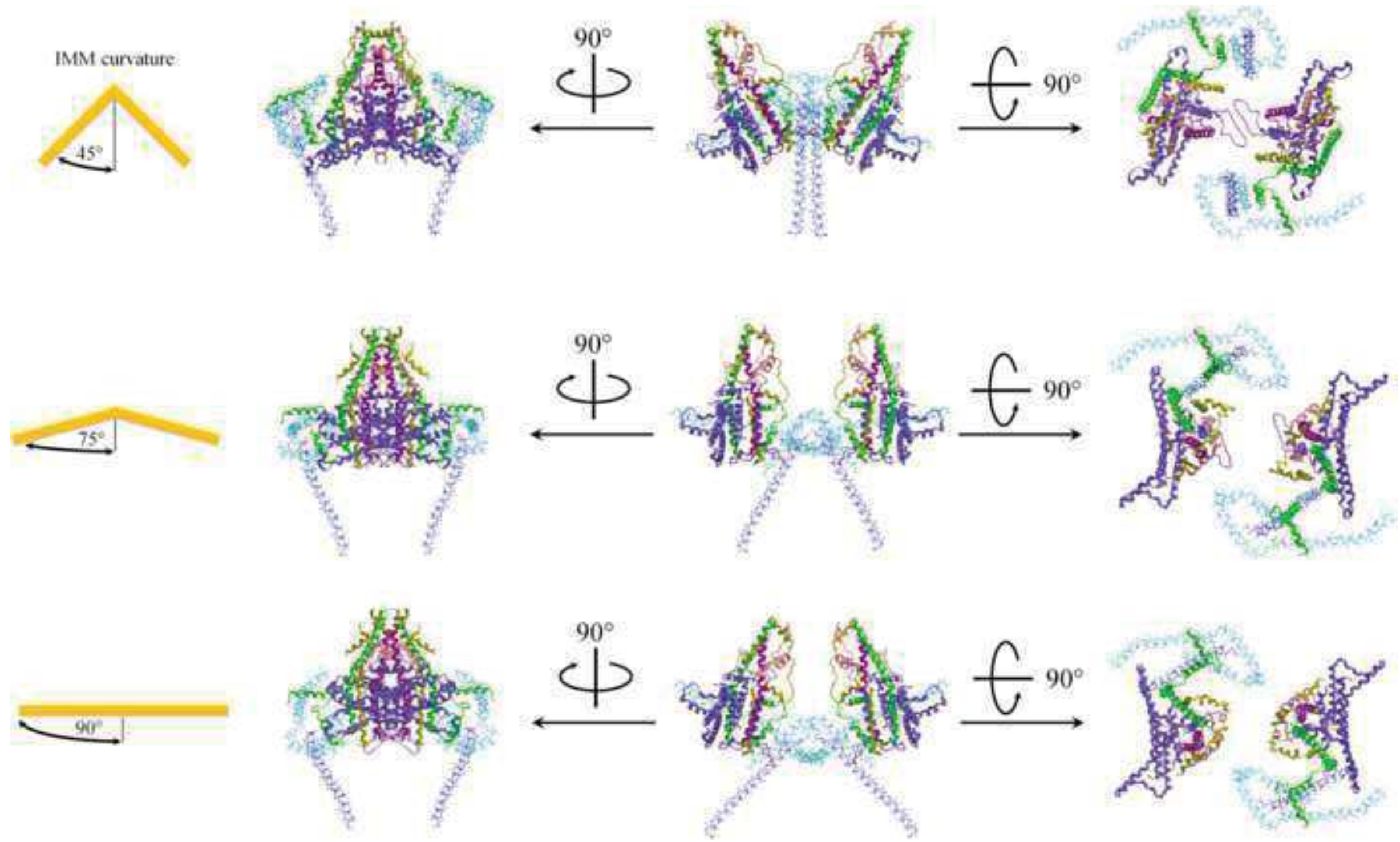